\title{
Methodological Framework for Investment Projects' Development (Design and Construction)
}

\author{
Virgil Profeanu \\ Ion Mincu University of Architecture and Urbanism \\ profeanuvirgil@gmail.com \\ Andreea - Mariana Manta \\ The Bucharest University of Economic Studies \\ andreeam.manta@gmail.com
}

\begin{abstract}
The purpose of the paper is to analyse the methodological framework applied in investment projects' development. It was considered the domain of design and construction projects. The paper identifies the main stages associated with the project's development, respectively the opportunity, fundamentation, financing and implementation. After analysing these documents, appropriate solutions were proposed to improve the efficiency of the evaluation process and the relevancy of its results. The solutions were based on the literature review that the authors carried out on the topic of investment projects' evaluation and on their professional experience as projects writers, evaluators and managers. The originality of the paper is supported by the innovative solutions proposed to the present problems that affect the investment projects' development in Romania.
\end{abstract}

Keywords: design and construction projects, project, development improvement, project life cycle, project evaluation

JEL Code: H43, O22, G11, D25, L74

\section{Introduction}

The article illustrates the present situation referring to the methodological framework applied for design and construction projects' development. The type of projects included in the present research are financed through public funds in Romania. Practical solutions are proposed according to the findings on the present situation.

The authors chose the present research theme due to the existing problems related to investment projects' development. Improving the present process of projects' development would contribute to a more efficient and effective use of resources and also would save time to implement a higher number of investment projects in a country that is deficient in investment projects and sustainable economic growth.

\section{Literature Review - present methodological framework}

Investments represent one of the most crucial factors in Romania's economic evolution as "Investments are the main element that can ensure the economic growth and be part of the country's sustainable development program." [1]

Popescu G. H. et al. (2019) study carried out in Romania "express the needs of massive investments in the national economy, in order to ensure an intensive growth, within the capital to get the prevalent role." [2]

As a result, the Romanian "Governance Program over the period 2018-2020"[3] has as one of the main objectives to obtain economic growth and to strengthen "fiscal budgetary sustainability by significantly increasing the budget-financed investments or by accelerating the absorption of the European funds and by stimulating private investment". [3]

The methodological framework applied for investment projects which involve design and construction works is legislated by "Government Decision no. 907/29.11.2016 regarding the 
stages of elaboration and the framework of technical - economic documentation related to the investment objectives/projects financed through public funds". [4]

The following table resumes the principal stages of design documentation in the case of a construction project development.

Figure 1 - Stages of designing an investment construction project [4]

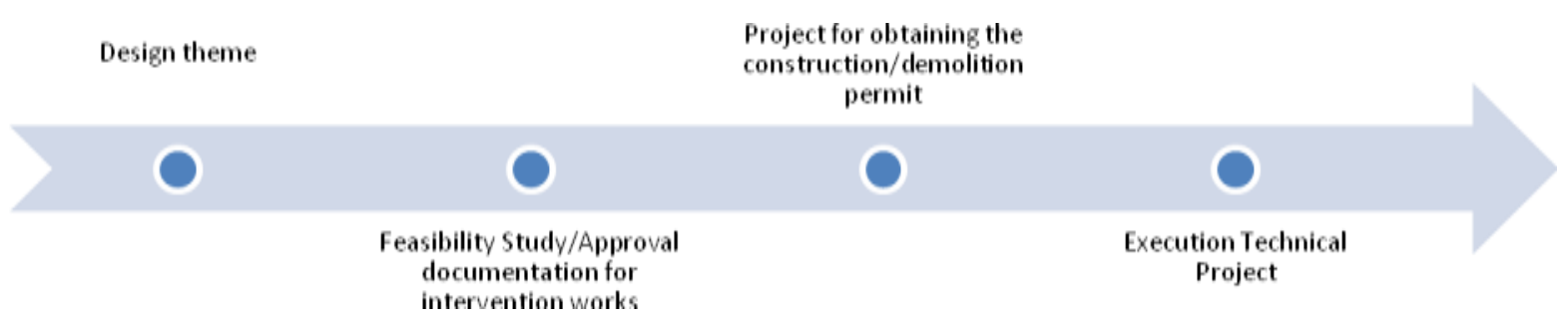

The documentation is elaborated in stages, as follows: the elaboration of a conceptual note and a design theme is requested in the first stage; the second stage implies the elaboration of a prefeasibility study, feasibility study or approval documentation for intervention works, the third stage involves perfecting the technical design project for obtaining the construction/demolition permit and the last stage includes preparing the execution tehnical project. [4]

The conceptual note and the design theme is the documentation drafted by the investment beneficiary in order to justify the necessity and the opportunity of developing an investment objective. [4]

The pre-feasibility study is the documentation that expands the anterior description of necessity and opportunity of developing the investment objective. It identifies possible technical economic scenarios and it selects a limited number of scenarios to develop the investment objective. The pre-feasibility study is drafted for major investment objectives/projects and is approved by the financing authority. [4]

The feasibility study is the technical - economic documentation through which the designer analyses, fundaments and proposes minimum two different scenarios, making a justified recommendation at the end of it. The recommended technical - economic scenario includes: the technical solution, the main technical - economic indicators related to the investment objective, the urban certificate, the approvals for utilities and other specific approvals and studies in accordance with the specific characteristics of the investment objective. [4]

The approval documentation for intervention works is similar to the feasibility study, based on the technical expertise of the existing construction. [4]

The general estimate and the object estimate is part of the feasibility study and of the approval documentation for intervention works and establishes the estimated value of developing the investment objective. [4]

The project for obtaining the construction/demolition permit contains technical details related to the future investment objective. It includes technical memoirs and drawings describing the recommended solution in the feasibility study. [4]

The execution technical project represents the documentation through which the designer develops, expands and optimizes the selected scenario in the feasibility study. This documentation subserves the constructor to build the future investment objective. [4]

However, the applicable legislation does not provide sufficient support to the development of invesment projects.

The results of Ignatov A. (2018) study entitled "Regional Development Discrepancies in the Eastern European Union Analysed through the Prism of Growth Determinants" highlights that there is an imperative need to enable the authority of "the EU to increase its ability to decide the 
issues related to discrepancies reduction, infrastructure investments and improvement of the regional business opportunities."[5]

Despite the fact that "The continuous legislative efforts of developing Romania's regions have resulted in strategies and projects to eliminate economic and social inequalities between regions" [6] repetitive problems appear in the development of investment projects.

One of the problems is the inadequate quality of work packages which "leads to losses such as increasing the costs, projects' delay and even bankruptcy of the projects' contractors. " [7] According to the World Bank Group synthesis on Romanian projects financed through national funds and European funds, there are serious challenges related to coordination presented in the following figure [8]:

Figure 2 - Challenges in Strategies, Investment Programs and Infrastructure Projects [8]

\section{Strategies}

Big number

Low quality (lack of objectives, budgets, priorities, indicators)

Lack of a formal process for development and improvement of the strategies

\section{Investment programmes}

Different approach among projects financed through national funds and those financed

through European Funds

Lack of clear separation of intervention domains

\section{Infrastructure projects}

Lack of continuity of the projects

Lack of integrated projects

Lack of adequate monitoring and evaluation of projects

Low quality technical documentation

The next chapter highlights some of these problems that affect the successful implementation of investment projects.

\section{Weaknesses in the projects' development process}

The chapter explores several problems affecting the investment projects' implementation in the design and construction domain.

The first problem the authors encountered in this process is represented by the request of the bill of quantities since the elaboration of the Feasibility Study. The Feasibility Study does not advance the technical details at the convenient level for developing the final bill of quantities.

In the normal case, in the Execution Technical Project stage, the beneficiary is informed about the potential cost modifications and can decide to change items of the design in order to lower costs or approve the increased value. [9]

However, in Romania in the case of investment projects financed through European Funds, the initial bill of quatities has to be respected exactly in terms of costs chapters values. Consequently, the architect along with all the engineers and quantity surveyors involved in designing the future investment objective make useless efforts to estimate the bill of quantities without relevant technical information. The outcome is a bill of quantities that is not correlated with the further execution technical project but that has to be respected in the subsequent stages of construction design. That is the reason why at the stage of developing the execution technical project the 
design team have to elaborate the final bill of quatities so that the values of the costs chapters from the initial bill are not modified. This represents an artificial effort that affect the real values of the costs involved in the construction stage.

The bill of quantitites is not requested in the Feasibility Study stage thorugh the applicable legislation, but the evaluators of the investment projects financed through European Funds always demand the elaboration of the bill in this early stage. This initial bill constrains the subsequent bill of quantities without adequate technical base.

The second problem that appears in the development of investment projects is represented by the considerable delays in the evaluation and procurement process. Therefore, the initial technical conditions taken into consideration in the Feasibility Stage or in the Execution Technical Project Stage do not appply anymore in the Implementation Stage. Hence, the present situation included in these initial documentations changes through the interminable period of evaluation. For example, in the case of a project coordinated by the authors, that involved desilting of a lake, the initial present situation included in the Technical Project was completely modified until the construction works started. This led to additional costs due to the spontaneous vegetation that appeared in the evaluation and procurement process period.

Moreover, in another project in which the authors were involved, the initial technical requirements associated to the equipments that were considered to be procured through European Funds were no longer available on the market when the project reached the implementation stage, as new generations of similar equipments replaced the initial ones. Therefore, the inital technical requirements could not be respected due to the long period of project evaluation.

In addition, the necessities that fundament a project suffer serious changes through the evaluation period. Consequently, the projects that are implemented do not respond to the updated necessities anymore. This leads to waste important resources.

Another very important problem that affects the investment projects' development is the lack of assumption of the approved project thorugh the implementation stage. This is one of the reasons why different evaluators can apply different correction measures in the process of project development. Therefore, it is a common practice for projects beneficiaries to receive contradictory recommendations and correction measures due to the changing evaluators. Evaluators of projects financed through European Funds do not take responsability for their recommendations and indications. It happens very often for implemented projects that passed through all the evaluation stages to be reconsidered in terms of eligibility. As a result, these projects receive correction measures and it is requested the reimbursement of the received and implemented funds, because the new evaluators involved in the post implementation stage have different opinions and interpretations on what their peers approved to be financed in the past.

The following chapter promotes potential solutions to the problems identified and described above.

Futhermore, one of the reasons for not making the right investment decision in the public sector is represented by the lack of pre-feasibility studies' development. In this way, great amounts of financial resources are lost in feasibility studies' development. It is well-known that feasibility studies do not analyse the investments taking into consideration the appropriate exploitation period of time and the future technologies involved. Consequently, public financial resources are allocated for investments that turn not to be useful during the whole exploitation stage.

In the case of investment projects financed through European Funds, the use of prices that are no longer up to date is a common problem. This leads to unrealistic estimation of costs for the project and to the impossibility of the project's implementation.

The obligation to maintain all the information associated to the investment as the one appearing in the feasibility study during all the projects' stages (for example: the title of the project cannot be changed). This constraint leads to the lack of the projects' updating after carrying out feasibility studies. In this way, relevant information resulting from the feasibility 
studies is not applied in the following stages of the projects' development affecting its implementation.

\section{Solutions proposed}

The solutions proposed are based on the authors' practical experience in developing investment projects involving construction works.

The first solution proposed is the replacement of the bill of quantities that is requested in the Feasibility Study Stage with a new form of estimation. The new form that the authors recommend implies the estimation of costs using the square meter as a measurement unit. This method proposes to estimate a maximum cost per square meter per investment objective. In this way, the necessary modifications related to the value of costs chapters and work categories generated by the further detailed execution technical project can be made without unjustified constraints. In addition, it involves establishing the maximum value of the investment project construction that would be respected in the subsequent stages.

The problem of delays in the evaluation and procurement process can be addressed through establishing fixed deadlines for evaluators and through a serious review of the applicable procurement legislation. The deadlines should be established in order to ensure the availability of the present situation taken into consideration in the initial stage of the project's development.

The review of the applicable legislation in public procurement should target a more reasonable maximum period of time for the process. In this regard, the potential obstacles in the way of successful completion of the procurement process should be eliminated. An example of these obstacles is represented by the possibility to easily contest the procurement process by any bidder. In this way, the procurement process can last an interminable period of time affecting the project implementation.

In order to eradicate the lack of assumption among the project evaluators, the authors propose the introduction of a new document that has to be approved and signed by the project's beneficiary and the project's evaluator through all the life cycle stages of the project. The document the authors propose is entitled the project's synthesis and includes information about: the financing agreement, designer's name, design theme, including the plot's surface, dimension and form, existing buildings, buildings that would be demolished, access ways, available utilities, urban networks that can affect the project, conditions imposed by the urban certificate, including the maximum percentage of land occupation, maximum coefficient of land use, height regime, building functions, construction retractions from alignment, from the side boundaries, from the posterior limit, built area, net area, constructive system, rooms' functions, intervention works on the existing zone, estimated number of users, aesthetic and finishing options, comfort standard, specific endowments, type of construction structure, installations, importance category and class of the building, level of fire resistance and other relevant technical information.

In this way, every evaluator takes responsibility of the approved projects' technical design and construction details. Nowadays, the beneficiary is the only involved part that takes all the responsibility for the investment project financed through European Funds.

Another solution proposed is the development of pre-feasibility studies. Firstly, major investments should always imply a pre-feasibility study in order to avoid spending financial resources on infeasible investments. The pre-feasibility study would be carried out using only available documents and information (eg: Google Maps, Google Earth). Consequently, this type of study would not include costs for topographic or geotechnical studies. In addition, a prefeasibility study should analyse the investment from a spatio-temporal perspective. For example, a potential investment is to create 20.000 car parking places in Bucharest. If analysed in the present, the investment appears to be feasible, as it is well-known that the city is missing enough car parking places. However, if future technology (such as: the volocopters development, the use of ridesharing and other means of transport in order to avoid busy traffic) and an exploitation period of 20 years are taken into consideration, the investment turns out to involve a great 
amount of risk as from this perspective, the car parking places would not be used $100 \%$. Consequently, the pre-feasibility study should evaluate the investment through the correct viable exploitation period of time and from the technology's future point of view.

Moreover, the pre-feasibility study should not exceed 20\% of the Feasibility Study's value, so that the investor would not lose a considerable amount of financial resources if the investment turns out not to be feasible.

In order to adjust the costs' estimation in the investment projects, the authors propose the establishment of unit prices per square meter of buildings that have the same function and the same height regime gathered in a common imposed database, prices that would be indexed with the appropriate discount rate.

Furthermore, the obligation to maintain all the initial information associated to the investment projects should be changed with the obligation to always update this information in accordance with each study's conclusions in order to have a relevant project for an implementable investment.

The following figure resumes the solutions proposed in comparison with the present situation:

Figure 3 - Solutions to problems in the development process of investment projects

Estimation of investment objective value in the feasibility study
In the present: Bill of quantities
Delays in the evaluation and procurement processes
In the present: Unterminable period of time for
evaluation and procurement without any deadlines
imposed

\section{Lack of pre-feasibility studies' development}

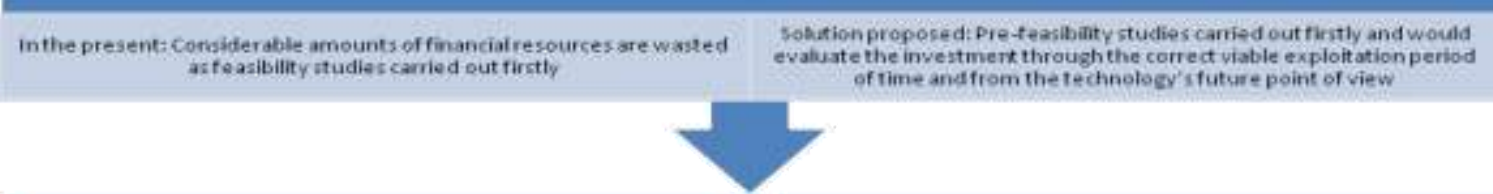

The use of prices that are no longer up to date

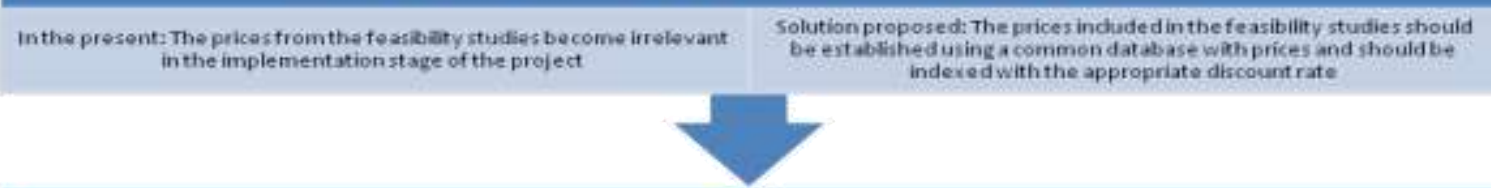

Obligation to maintain all the information associated to the investment

Inthe present-it is compulsory to maintain all the information ssociated to the investment during the entire life-cycle of the project
Solution proposed: The obligation fo update the information assodiated to the investment in accordance with the studies' conclusions 
The project synthesis would be developed and signed in the Design Theme Stage, Feasibility Study Stage, Project for obtaining the construction permit Stage, Execution Technical Project Stage and in the Implementation Stage.

\section{Research methods and principles}

The present paper was elaborated using various methods.

The first method that the authors applied was the review of the available publications related to the investment projects' development in Romania.

Another method was the observation in the authors' practical experience in development of investment projects financed through European Funds.

The synhesis document regarding the approved project's details was proposed in the spirit of the principles of inclusiveness, open decision making and freedom of information, so that the beneficiaries benefit from the possibility to have access to transparent information from the evaluators, "interact and participate in decision making". [10]

\section{Conclusion}

The present problems that affect the investment projects development have to be analysed and treated through appropriate solutions.

The article explored six of them and proposed practical solutions.

In the absence of applying appropriate solutions to the existing issues, the economic situation in Romania will not be improved and its economic growth will be jeopardized.

The authors strongly believe that the solutions proposed would considerably improve the present situation and would promote the elaboration of similar ideas in order to ameliorate the process of investement projects' development.

\section{References}

[1] Anghel M.G., Avram D., "The role of investments and business environment in economic development", Romanian Statistical Review - Supplement nr. 10 / 2018, available at: bttp:// wnw.revistadestatistica.ro/supliment/wp-content/uploads/2018/10/rrss_10_2018_A3_en.pdf, accessed: 10.05.2019;

[2] Popescu G.H, Andrei J.V., Nica E., Mieila M, Panait M, Analysis on the impact of investments, energy use and domestic material consumption in changing the romanian economic paradigm, TECHNOLOGICAL AND ECONOMIC DEV ELOPMENT OF ECONOMY, Volume: 25 Issue: 1 Pages: 59-81, 2019, available at: DOI: 10.3846/tede.2019.7454; apps.webofknowledge.com.am.enformation.ro/full_record.do?product $=$ WOS \&search_mode $=$ GeneralSearche $q i d=11 \& S I D=D 1+K h 1 v \mathrm{cwBy}$ mvvV5Epu\&opage=1\&doc=12, accessed: 10.05.2019;

[3] Ciurea M., "The Public-Private Partnership in Romania-Theoretical Approaches", Quality - Access to Success, Suppliment 1, Vol. 20, p457-462, 2019, available at:

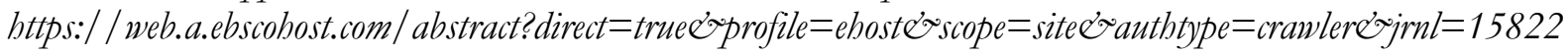

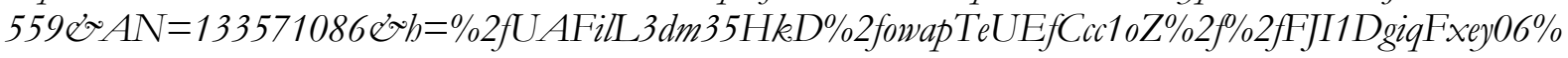

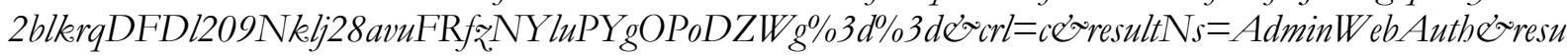
It Local $=$ ErrCrINot Authe crlhashurl=login.asp $x \% 3$ fdirect $\% 3$ dtrue $\% 26$ profile $\% 3$ dehost $\% 26$ scope $\% 3$ dsite $\% 26$ authtype\%3dcrawler\%26jml\%3d15822559\%26 AN\%3d133571086, accessed: 10.05.2019;

[4] Government Decision no. 907/29.11.2016, Romania, available at: http:// legislatie.just.ro/Public/DetaliiDocument/185166, accessed: 10.05.2019;

[5] Ignatov A., "Regional Development Discrepancies in the Eastern European Union Analysed through the Prism of Growth Determinants" Global Economy Journal, Vol. 18, No. 4, 20180078 (2018), available at: bttps://doi.org/10.1515/gej-2018-0078; https:// wnw.worldscientific.com/doi/abs/10.1515/gej-2018-0078, accessed: 10.05.2019;

[6] Dobre I., Pantilie A.M., "The impact of public institutions projects in the economic and social development of South-Muntenia Development Region" Quality - Access to Success, Vol. 18, Iss. S2, March 2017, pages 189- 
194, available at: https://search.proquest.com/openview/4c75f3a0f4c48500ca24a946cf675df7/1?pqorigsite = gscholare cbl=1046413, accessed: 10.05.2019;

[7] Mojtaba A. M, Saeed Y., Mohammad R.M.A, "An optimal control model for analyzing quality investment in the project management" Computers \& Industrial Engineering, Volume 129, March 2019, Pages 529-544, available at: https://mwn.sciencedirect.com/science/article/abs/pii/S0360835219300816, accessed: 10.05.2019;

[8] Harmonizing State and EU Funded Projects in regions - Final Synthesis, The World Bank Group, 26 November 2015, available at: documents.worldbank.org/curated/en/952051468196173628/pdf/104755ROMANLAN-WP-P147062-PUBLIC-Harmonizing-State-and-EU-Funded-Projects-Final-Synthesis.pdf, accessed: 10.05.2019;

[9] Farshid R., "Importance of Quantity Surveyors for public sector organisations in the prevaling recession" available

bttps:// www.academia.edu/466357/Importance_of_Quantity_Surveyors_for_public_sector_organisations_in_t be_prevaling recession, accessed: 10.05.2019;

[10] Service standards and principles, available at: https: / ec.europa.eu/info/ about-european-commission/servicestandards-and-principles/inclusiveness_en, accessed: 10.05.2019. 